Reviewed Article: Teaching and Learning in Clinic

\title{
ENHANCING EMOTIONAL COMPETENCIES WITH LAW STUDENTS
}

\section{Colin James and Felicity Wardhaugh*}

\section{The University of Newcastle and the Australian National University, Australia}

This paper follows a preliminary report titled 'A Client-Focused Practice: Developing and Testing Emotional Competency in Clinical Legal Interviews'. It provides the final results of research with students at the University of Newcastle Australia that was designed to test ways to enhance emotional competencies in clinical placements.

\section{A INTRODUCTION}

In our earlier paper we discussed why it is becoming increasingly important for law students to be introduced to the concept of EI and provided with the opportunity to develop and enhance their EI abilities. ${ }^{1}$ As stated there, the Teaching and Learning Outcomes (especially TLO 5) in legal education recognise that employers expect law graduates to have well-developed self-awareness and the kind of good communication skills that require emotional capacities. ${ }^{2}$ While this study involves students on placement in a community legal centre practice, the need for law students to enhance their emotional

\footnotetext{
* Felicity Wardhaugh is a Solicitor in private practice and Colin James is a Senior Lecturer at the Australian National University, ANU College of Law Legal Workshop. During this research both researchers were clinical legal educators at the University of Newcastle Legal Centre (UNLC), Australia. ${ }^{1}$ Felicity Wardhaugh and Colin James, 'A Client-Focused Practice: Developing and Testing Emotional Competency in Clinical Legal Interviews' (2014) 20 Volume II International Journal of Clinical Legal Education, 633-645.

${ }^{2}$ Anna Huggins, Sally Klift and Rachael Field, 'Implementing the Self-Management Threshold Learning Outcome for Law: Some intentional design Strategies from the Current Curriculum Toolbox' (2011) 21(2) Legal Education Review 183.
} 
capacities is just as significant for commercial legal practice. In fact, commercial practice often involves billing clients based on time spent which potentially adds another level of stress for the lawyer requiring well-developed emotional competence.

The concept of emotional intelligence (EI) is relatively recent although the relevance of human emotion has been reflected upon for centuries. ${ }^{3}$ In the early $20^{\text {th }}$ century, psychologists developed 'IQ' tests to measure intelligence. ${ }^{4}$ In the 1990s the possibility of a social intelligence or EI caught the imagination of the public. ${ }^{5}$ Unsubstantiated claims about the benefits of EI and controversy over whether it should be considered an 'ability' or a 'trait' led to distrust about its validity or measurability, however some wellrespected tests emerged. 'Ability' EI is usually measured through problem-solving tests, which are similar to those used in intelligence tests. ' ${ }^{7}$ Trait' EI is typically regarded as aspects of character, and includes motivation and social competency, and is generally measured using self-report tests. ${ }^{8}$

\footnotetext{
${ }^{3}$ Aristotle discussed the role of emotions in his work on moral virtue in his lectures published as 'Nicomachean Ethics'

${ }^{4}$ Possibly the first IQ test developed was by Binet-Simon to help assess which school children may need assistance. Alfred Binet and Theodore Simon, The Development of Intelligence in Children (Williams \& Wilkins, 1916)

${ }^{5}$ Daniel Goleman, Emotional Intelligence: Why it can matter more than IQ (Bantam Books, 1995)

${ }^{6}$ For a discussion of this development see Elizabeth J Austin and Donald H. Saklofske, 'Introduction to the special issue on emotional intelligence' 65 (2014) Journal of Personality and Individual Differences 1. 7 J.D. Mayer, D. Caruso and P. Salovey, 'Emotional Intelligence Meets Traditional Standards for an Intelligence' (1999) 27(4) Intelligence 267;M. Brackett and P. Salovey, 'Measuring emotional intelligence with the Mayer-Salovey-Caruso Emotional Intelligence Test (MSCEIT)' (2006) 18 (Suppl.) Psichothema 34. ${ }^{8}$ R. Bar-On, 'The Bar-On model of emotional-social intelligence (ESI)' (2006) 18 suplement Psicothema 13; R. Bar-On, 'The Emotional Quotient Inventory (EQ-i): A test of emotional intelligence' (1997) (Toronto,Multi-Health Systems, Inc.).
} 
The ability model of EI postulates people have four broad 'domains', the ability to perceive emotions, to use emotion to facilitate thinking, to understand emotions and to manage emotions. These abilities are broadly conceived and interrelated so that our ability to perceive emotions includes our perception of other people's emotions as well as our own. Understanding emotions includes appreciating likely causes behind certain emotions. The fourth ability, the management of emotions, includes our ability to regulate our emotional state, as well as to interact effectively with other people's emotions and feelings. ${ }^{9}$

In seeking to improve students' EI, the authors favour the ability construct of EI over the trait model. A belief that students can improve their EI is consistent with findings on neuroplasticity and our capacity to learn from experience, as explained by the theory of 'growth mindset'. ${ }^{10}$

The research into EI challenges the historical cognitive dominance, whereby lawyers privilege "thinking" over "feeling" in legal education and practice. The conventional, dualistic view that thinking and feeling act as separate functions is now complicated by the probable inseparability of cognitive and affective interactions in how we process

\footnotetext{
9 Mayer J.D., Salovey, P and Caruso, D.R 'Emotional Intelligence: Theory, Findings and implications' (2004) 15 Journal of Psychological Inquiry 197 See also Davies, M., L. Stankov, and R.D. Roberts. (1998). 'Emotional Intelligence: In Search of an Elusive Construct.' 75(4) Journal of Personality and Social Psychology, 989

${ }^{10}$ Kathrin Koch et al, 'Extensive learning is associated with gray matter changes in the right hippocampus' (2016) 125 NeuroImage 627; Carol S. Dweck, Mindset: The new psychology of success (Ballantine, 2007).
} 
information and make decisions. ${ }^{11}$ Research into what makes an effective lawyer now supports EI as a necessary skill for lawyers, ${ }^{12}$ and EI has become a professional characteristic that is leveraged in promises of a caring approach with clients:

Each of our lawyers and conveyancers are as personable and approachable as we are knowledgeable and serviceable. We have the emotional intelligence to understand almost any legal situation and, just as importantly, you, our client. ${ }^{13}$

Despite the apparent openness to EI in the legal profession, legal education has been slower to respond. Changes have begun however, and initiatives are emerging in legal education to help law students improve their EI ability. ${ }^{14}$ Some clinical law schools are incorporating aspects of EI into the curriculum, for example when students learn about 'active listening' in dispute resolution. ${ }^{15}$ Similarly, students learning the practice of mediation are encouraged to use insight to understand the situation of the other side, and

\footnotetext{
${ }^{11}$ Antonio Damasio, Descartes' Error: Emotion, Reason, and the Human Brain, (Penguin, $2^{\text {nd }}$ ed, 2005) and Immordino-Yang M, Damasio A. 'We feel, therefore we learn: the relevance of affective and social neuroscience to education' (2007) 1 Mind Brain Education 3.

${ }_{12}$ Marjorie M. Shultz \& Sheldon Zedeck, 'Predicting Lawyer Effectiveness: Broadening the Basis for Law School Admission Decisions, (2011) 36 Law \& Society Inquiry 620. Susan Daicoff, 'Expanding the Lawyers' toolkit of skills and competencies, synthesizing Emotional Intelligence, Conflict Resolution and Comprehensive Law" (2015) Santa Clara Review, 795.

${ }^{13}$ Di Rosa Lawyers < http://dirosalawyers.com.au/about/meet-the-team >21 November 2015 ${ }^{14}$ Nathalie Martin, 'Think like a (Mindful) Lawyer: Incorporating Mindfulness, Professional Identity, and Emotional Intelligence into the First Year Law Curriculum' (2014) 36 (3) University of Arkansas at Little Rock Law Review 413. This follows earlier work such as Marjorie Silver, Emotional Intelligence and Law (1999) 5(4) Journal of Psychology, Public Policy and Law 1173, and John Montgomery (2008) 'Incorporating Emotional Intelligence into Legal Education, strengthening the professionalism of law students 39 University of Toledo Law Review 322.

${ }^{15}$ Nadja Alexander and Jill Howieson, Negotiation Strategy Style Skills (2nd Ed., 2010) LexisNexis Butterworths (Chapter 8). Roger Fisher and Daniel Shapiro, Beyond Reason, Using Emotions as You Negotiate (Penguin, 2006)
} 
to consider if developing a more empathic approach might help resolve the dispute. ${ }^{16}$. In addition, some law schools incorporate discussions of EI as an aspect of professional resilience training, in response to research showing law students typically experience a deterioration in their mental health as they progress through law school. ${ }^{17}$ Consistently, other research shows the ability to express and interpret personal emotions often corresponds with improved wellbeing. ${ }^{18}$

Despite the significant increase in empirical and theoretical publications applying, advocating and critiquing the utility and validity of EI, including its relevance in legal practice, the authors could find no research testing whether training in emotional competency could improve the way a law student performed on placement in a legal clinic.

\section{B THE RESEARCH HYPOTHESIS}

The presumption for the hypothesis was that a practical training program enabling law students to develop their EI competencies, going further than merely helping them to

\footnotetext{
${ }_{16}$ Robert A Barusch Bush, 'Mediation Skills and Client-Centered Lawyering: A New View of the Partnership (2013) Clinical Law Review 19, 429. See also Susan L. Brooks, 'Using a Communication Perspective to Teach Relational Lawyering' (2015) 5 Nevada Law Journal 477, where Brook's approach to teaching communication skills to lawyers includes aspects of EI.

${ }_{17}$ Rachael M. Field and James Duffy, 'Law student psychological distress, ADR and sweet-minded, sweeteyed hope' (2012) 23(3) Australasian Dispute Resolution Journal 195.

${ }_{18}$ Martins, A., Ramalho, N. and Morin, E. 'A comprehensive meta-analysis of the relationship between emotional intelligence and health' (2010) 49 Personality and Individual Differences, 49; Brian S. Clarke, 'Coming Out in the Classroom: Law Professors, Law Students and Depression' (2015) 64(3) Journal of Legal Education 403.
} 
understand theories of EI, would help them in their practice as lawyers.

Consequently, the hypothesis was that students who participate in an EI training module will perform better, as measured by their respective clients, by their supervisors and by self-assessment, in a first legal interview, compared with a control group of students who do not participate in the training. More information about preparation for the project is detailed in the earlier paper. ${ }^{19}$ Briefly, the authors devised a training program to improve students' emotional competency and attempted to test the effectiveness of the program using students' first interview of live clients attending a legal clinic, by analyzing responses and feedback from the clients.

\section{The clinical setting}

The research took place at a community legal centre (XXXXX), a general legal practice funded by the XXXXX, as part of the XXXXX Law School. The centre provides free legal assistance to members of the community in a 'drop in' legal advice clinic and is also a vehicle for teaching students legal practice skills such as client interviewing, in a clinical module. Students are enrolled in the University's Practical Legal Training (PLT) program, integrated with their last two years of academic legal study, and once completed they are eligible for admission to practice as a lawyer. The XXXX program requires students to work 360 hours over a 2-year period, of which the first 90 hours is at the centre and the balance can be at another legal practice or organisation in the

${ }^{19} \mathrm{XXXXXX}$ 
community. The program includes class-room teaching, which complies with the course content requirements of the Solicitors' Admission Board. The students who participated in this research were $4^{\text {th }}$ year students in their first 90 hours of placement at the clinic. Participants included both graduate and undergraduate students predominantly aged in their twenties. Most had no prior experience of legal interviewing, because the research took place in their first semester of the PLT program. Based on the PLT program being an 'admission stream' and on the authors' experience over many years teaching in that stream it was assumed that most students in the program were seeking admission to practice.

During 2013 and 2014, the clinic operated on Wednesday mornings and clients attended seeking legal advice on issues typically encountered in a general practice community legal centre, such as family law, criminal law, employment law, tenancy disputes and deceased estates. Students met the clients and asked them to complete a form giving information about themselves and their legal problem. The students then escorted the client to an interview room. The student who conducted the interview enquired about the client's case (the first stage) but did not provide legal advice to the client. Once the student was satisfied that he or she understood the legal problem the student asked the client to wait, and left the interview room to find a supervising lawyer. The student then discussed the case with the supervisor (out of client earshot) and the student, together with the supervisor, decided on legal advice for the client. Both the supervisor and 
student returned to the client in the interview room where the supervisor provided legal advice to the client (second stage) with the student observing and assisting. This research sought to make use of the time gap between the first and second stages, which provided an opportunity for questionnaires to be completed by all three participants in the process: the client, the student and the supervisor.

\section{Ethics}

The university's Human Research Ethics Committee granted approval for the research on 25 October 2012 (H-2012-0368). Subsequent procedural amendments were also approved as variations.

\section{Method}

A research assistant (RA) was employed to communicate with participating clients and students and to distribute research information sheets. If the client agreed to participate, the RA produced a questionnaire and asked the client to complete it during 'the gap' whilst waiting for the student to return with a supervisor. The number of clients who refused to participate in both 2013 and 2014 was insignificant.

The RA also explained the research to the students, provided them with an information sheet and invited them to consider participating. Similarly, supervising lawyers were informed of the project and invited to participate. In both years all students invited to participate agreed to do so. Four of the six supervising lawyers participated. ${ }^{20}$

\footnotetext{
${ }^{20}$ The authors were not participants.
} 
The research began with a pilot study in 2012, as discussed in our earlier paper. ${ }^{21}$ The main research involved 2 cohorts of students. The first cohort in 2013 was the 'control' group, which consisted of 56 students who received no additional training, and conducted 118 client interviews. The second cohort in 2014 was the intervention or 'experimental' group of 64 students who conducted 122 interviews after receiving four weeks of additional 'intervention' training.

The research design involved a mixed method to test the hypothesis, using a questionnaire combining quantitative and qualitative questions. Both the client and student questionnaire involved eight quantitative questions using a Likert scale. ${ }^{22}$ The questionnaire for clients combined elements from earlier studies in legal and medical education. ${ }^{23}$ The clients' questionnaire is shown at Figure 1. For each question clients were asked to respond: 'unsure/don't know - strongly disagree - disagree - agree - strongly agree'.

\footnotetext{
${ }^{21}$ Wardhaugh and James, above n. p.638.

22 A likert scale is a common form of scaling responses in survey research like this. Here, a similar questionnaire instrument was used for the supervisors but it was reduced to 5 questions. Supervisors in the pilot expressed concern that they were unable to answer some of the questions because they had not seen the student and the client interact in the first stage of the interview process.

${ }^{23}$ Barton, K., Cunningham, Jones, C.G., Maharg, P, 'Valuing what clients think: standardized clients and the assessment of communicative competence '(2006) 13(1) Clinical Law Review 65. Mercer SW et al, 'Relevance and practical use of the Consultation and Relational Empathy (CARE) Measure in general practice' (2005) 22 (3) Family Practice 328. Mercer SW et al (2004) 'The development and preliminary validation of the Consultation and Relational Empathy (CARE) Measure: an empathy-based consultation process measure' 21 Family Practice 6, 699-705.
} 


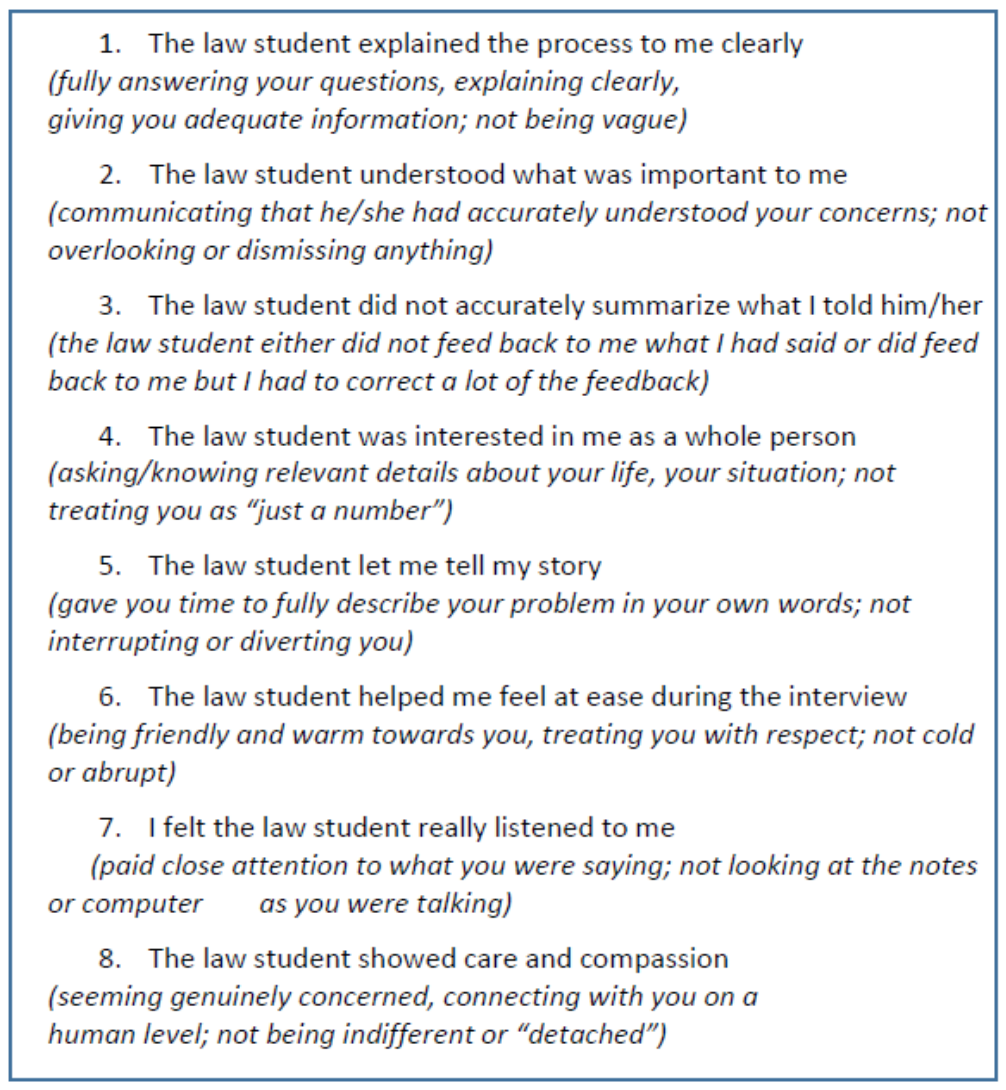

Figure 1.

There were also two qualitative open questions in the client questionnaire:

1. 'Please use the space below if you would like to explain how the student could improve upon their interviewing skills' ('the improvement question'), and

2. 'Please use the space below if you would like to explain any of your answers to the questions on the survey' ('the explanation question').

The pilot test in 2012 had indicated significant participant bias as most clients gave very

positive answers to all questions. In response we varied the questionnaire and included

"the improvement question" to encourage clients to be more candid about the interview

process. 


\section{The research periods}

The control group interviews took place between 10 April 2013 and 29 May 2013 and the intervention group interviews took place between 7 April 2014 and 11 June 2014. For each cohort the research commenced in the $5^{\text {th }}$ week of the first semester so that the control group of students and the intervention group of students were at the same point in their studies both in the clinic and their other doctrinal subjects. The difference was that the intervention cohort received 4 weeks of EI training before the research commenced whilst the control group did not.

\section{STEU testing}

Students in the control group and the intervention group were each tested before and after the research period using the situational test of emotional understanding instrument. ${ }^{24}$ The STEU questionnaire was developed by MacCann and Roberts for use in EI research and has been tested to show good validity. ${ }^{25}$ Whilst the MSCEIT test is commonly used in EI studies the cost was prohibitive for this project. ${ }^{26}$ The multiple choice format of STEU is designed to test understanding of 14 different emotional states,

\footnotetext{
${ }^{24}$ MacCann, C., \& Roberts, R. D. 'New paradigms for assessing emotional intelligence: Theory and data' (2008) 8 Emotion 540

${ }^{25}$ Nele Libbrecht \& Filip Lievens, ‘Validity evidence for the situational judgment test paradigm in emotional intelligence measurement' (2012) 47 (6) International Journal of Psychology 438. Veleka D. Allen et al, 'Development of the situational test of emotion understanding - brief (STEU-B) using item response theory' (2014) 65 Personality and Individual Differences 3.

${ }^{26}$ Mayer, J.D., Salovey, P. and Caruso, D., Mayer-Salovey-Caruso Emotional Intelligence Test (MSCEIT), (2002) Multi-Health Systems, Toronto.
} 
which was suitable to capture before and after levels for the students in both control and intervention cohorts.

\section{THE TRAINING MODULES FOR THE INTERVENTION GROUP}

The intervention training aimed to assist students recognise the importance of emotions in legal practice and to facilitate development of their emotional competencies whilst developing their interviewing skills in a clinical setting. The structure of the intervention consisted of 8 hours of training over four weeks being $4 \times$ two-hour, weekly seminars. The intervention included engaging the students using class discussion, video simulations, class exercises, as well as a guest speaker and visual presentations on specific topics associated with current knowledge on emotions and their relevance in legal practice.

\section{Overall approach to the intervention training modules}

The authors sought to make the intervention development seminars engaging, creating a relaxed, informal atmosphere in class to encourage the students to participate as fully as possible. One assumption was that students at different stages of emotional competency would learn best from active participation and by listening to different perspectives and reflections, and by engaging with each other. ${ }^{27}$ We used a diverse range of colour imagery

\footnotetext{
${ }^{27}$ Research in the business field suggests EI competencies are best developed 'on the job' through group dynamics. N. Clarke 'Developing Emotional Intelligence through team-based learning' (2010) 21 Human
} 
and audio in our presentations as well as humour in entertaining video clips. We devised activities as learning tools so that students were not passively sitting in class, and we helped them focus by 'banning' the use of laptops, tablets and smart phones in class and persuading the students of the value of being present, and reflecting on the immediate content of discussions without taking notes, or checking their messages.

Overall, the training aimed to help students improve their abilities to identify, understand, use and manage their emotions, specifically in a client interview situation.

\section{The ability to understand emotion}

Due to the emphasis in law school on cognitive performance we expected the students to be consciously trying to 'think like lawyers'. The study and practice of law has been portrayed as a 'cognitive and rational' process, where emotions need to be eliminated for better decision-making. ${ }^{28}$ One student explained this perspective well:

Based on my law studies in previous years, I was under the impression that a legal professional should be as neutral or emotionless as possible when engaging with their clients, so as to maintain a professional working relationship with the client, to approach their legal matters objectively, and so as to not become personally invested in their cases.

Attempting to leverage any cognitive bias in the students' thinking we began by focusing on the cognitive dimension of the training. We invited a clinical psychologist to present

\footnotetext{
Resource Development Quarterly 119; P Moriarty and F Buckley 'Increasing team emotional intelligence through process' (2003) 27 Journal of European Industrial Training 98

${ }^{28}$ Gerald F. Hess, 'Heads and Hearts: The Teaching and Learning Environment in Law School' (2002) 52(1 \& 2) Journal of Legal Education 75
} 
to the students on the topic of 'Emotions and the Law' with a view to helping the students to start thinking about the role and importance of emotions, the science behind theories of emotion and to begin the process of understanding how emotions may inform our thinking, decisions and behaviour. The speaker was engaging, amusing and informative and appreciated by the students:

the things that Professor XXXX said were important because as someone who may potentially end up being a practising lawyer it's important to see potential clients as human beings with the same vulnerabilities as you

The speaker demonstrated the potential presence of cognitive bias through a short interchange with a student. When a student was asked: 'how do you feel_about your partner?' she responded: 'I think he is awesome' - providing a 'cognitive' response to a question about emotions. $^{29}$

Other intervention activities involved strategies to help the students realise how their values can affect their emotional responses. One exercise used a provocative scenario by Jonathon Haidt. ${ }^{30}$ The story involves a brother and sister who have sexual intercourse while on a holiday. They use a contraceptive and afterwards decide the experience was good but agree not to do it again. Students were asked to notice how they felt about the story:

\footnotetext{
${ }^{29}$ As the psychology lecturer pointed out, people typically find it hard to openly express their emotions and tend to hide behind a 'safer' response. When he pressed the student she quietly said 'well, I love him' but it felt very awkward.

${ }^{30} \mathrm{~J}$ Haidt, 'The emotional dog and its rational tail: A social intuitionist approach to moral judgment' (2001) 108 Psychological Review 814
} 
I really enjoyed the exercise where we were required to decide whether we thought that it was okay or not okay for a brother and sister to make love. I realised that the point of the exercise was to show how our 'emotional brains' can take over before our 'rational brains' are able to kick in.

I was sitting next to [X ] and she immediately circled 'No' but I held back and considered if there were any rational reasons for circling 'No'. We had a heated discussion because [she] realised that she could not explain why she circled 'No', only that 'it was disgusting'. However, I do not have a brother and therefore was able to consider the matter more objectively .....

My immediate thought was 'eww'! However, when I tried to [write] down my reasons for this response. I could not think of any rational reasons. I had no personal reason to think that what they did was wrong besides a gut feeling that it wasn't right. I just believed it was wrong. So then, I considered writing that I thought it was okay.

Looking at it from a rational point of view I can see that the actions of the brother and sister do not affect me personally. They were both consenting adults and it was a one-time thing that did not have any future consequences. In the end, I could not bring myself to answer yes ....my emotional response won the debate.

\section{The Reflection Process in understanding emotions}

Students in the intervention group were asked to write a reflection paper each week for the first three weeks to explore how the issues examined in the seminars might help them understand the relevance of EI in their legal placement, and for them as a beginning legal professional. The researchers gave qualitative feedback to each student with a personalized and supportive response. 
The reflection process required students to intentionally pay attention to feelings, and to the likely feelings of the client. Students were asked to notice their emotions in working with clients, to question their feelings and decide whether it was helpful or unhelpful in assisting their analysis of the case and giving the client the best possible legal assistance. By responding to each student reflection, the authors were able to facilitate and in many cases improve the students' engagement with the reflection process. Typical responses to students were:

In your next reflection, I want you to go deeper and discuss the emotions you think a client might have had, and how they may have affected their communications and decisions. Also what were your emotions, and how did they affect your behaviour?

...you describe a narrative of events rather than reflecting on your emotions or those of another in an interview situation..... try to recall the apparent emotions of ...client you interviewed. There are many things you can reflect on, eg. what were your emotions at the same time? How do you think the client's emotions affected their thinking and communication, and how did your emotions affect yours?

The following short extracts show how the reflective process apparently helped one student shift their perspective from 'descriptive' to 'reflective':

Student A - first reflection:

It is very important to be patient. As a lawyer, I would like to make my client feel comfortable and I would like to create a relationship of trust.

Student A - final reflection:

I think that maybe he just wanted to be heard. From watching the video clip, the client really seemed to just want someone to try and understand him..... 
The reflections gave the subsequent classes more salience by enabling us to incorporate issues raised in class discussions. Further, some students developed enough trust to use their reflections to disclose difficulties they were experiencing when interacting with clients. Our responses to the students helped break down barriers, which in turn led to further improved trust and more open discussions in class.

\section{Perceiving Emotions in oneself}

In helping students improve their capacity to recognise their own emotions, we suggested they become 'a student of me' and learn their own emotional 'triggers'. We introduced 'emotion cards' to demonstrate the large number of emotions for various situations, to discuss how emotions can be fleeting, multiple or confusing, and to demonstrate the difficulties some have in identifying and recognising emotions. ${ }^{31}$

\section{Perceiving emotions in others}

To help students understand the challenge of recognising emotions in others we organized several group activities. One activity involved 'emotional charades'.$^{32}$ Students were placed into groups of five and one member was instructed to be an 'actor'. The actor was asked to 'replicate' the emotion, without speaking, of how they might feel on walking out of a performance review where they were told their work was poor.

\footnotetext{
${ }^{31}$ We used the 'Emotions Cards', published by the Langley Group http:/hub.langleygroup.com.au/shop/category/cat13629/Facilitation and Coaching Tools.html. N Ashkanasy, Charmine E J Härtel and Catherine S Daus, 'Diversity and Emotion: The New Frontiers in Organizational Behavior Research' (2002) 28 Journal of Management 307.

32 David R Caruso, Peter Salovey, 'The Emotionally Intelligent Manager' (Jossey Bass, 2004), p.89
} 
There was lively discussion afterwards whilst the class worked through whether they had identified what the actor was feeling. Subsequent student reflections captured their thinking about others' comments:

When people started to describe the emotion that they picked up on, I initially thought that everyone must have had different scenarios. I was surprised when I realised that everyone had the same scenario, but had expressed it in different ways.

It was surprising how people chose to express the emotion in many different ways, from energetic anger all the way down to quite introverted emotions like uncertainty. The other thing I found surprising, was how hard it was to describe the emotion I had witnessed. I thought it would be easy to describe disappointment, but when I started thinking about it, I found it really hard to put into words.

I found it very interesting just how varied the individual responses were. Nearly everyone who 'acted' came up with a different emotion to the same situation, and for those who did act out the same emotion, each portrayal was unique.

Some people had very loud, over the top reactions, whilst others simply slumped in their chairs. It seemed I had a very naive view of just how varied people's emotional reactions can be. I never knew there were so many ways to exhibit 'frustration' or 'anger.'

Research suggests we have a natural tendency to perceive emotion from within our own cultural frame and to judge others only from what we can see, which in a legal interview may be a small part of a client's reaction. ${ }^{33}$ To make this a more realistic experience for students we devised a practical exercise. Working in pairs, one student was given a pen and informed (separately) that the pen was very valuable for emotional reasons (it

\footnotetext{
${ }^{33}$ Constantin Bratianu and Ivona Orzea, 'Emotional Knowledge: the Hidden Part of the Knowledge Iceberg', Management Dynamics in the Knowledge Economy (Tritonic Books, 2014), Volume 2 at 41.
} 
belonged to a deceased family member) and they were to resist any attempt by their partner to borrow it and, on no account, were they to give a reason for refusing to surrender the pen. The other student, uninformed of the instructions to the first student, was given one minute to persuade their partner to lend them the pen. We anticipated that this exercise would appeal to law students who see themselves as strong advocates. By the end of the activity only one student had successfully borrowed the pen, and then only for a 'few minutes'. This simple activity appeared to have a profound effect on some students:

I do .... find this class quite unsettling. .... For example, the pen exercise that we did this week; I think this was a really beneficial exercise to show that it is extremely difficult to communicate effectively with clients when there is so much built up inside them or 'under the surface of the iceberg' that we do not know about or understand.

The exercise about the pen ........ (I) failed to understand that he may have been grieving the loss of his father and upset by the way in which the funeral home handled the funeral.... At this stage, class discussion included the simple practices we can adopt as lawyers to help identify and acknowledge emotion in our clients. These include being mindfully 'present' with the client, looking at them as they speak, listening to them carefully and asking considerate questions. Research suggests that recognising emotional cues from clients can be as simple as noticing how they are behaving. ${ }^{34}$ For example, according to Gay Gelhorn, noticing the first words uttered by the client can be very helpful:

\footnotetext{
${ }^{34}$ Jennnifer K Robbenolt and Jean R Sternlight, Psychology for Lawyers (American Bar Association, 2012), 196
} 
[C]lients demonstrated that they will reveal critical material as soon as they have an opportunity to speak .... These revelations some- times occurred in the phase of an interview generally regarded as solely serving the purpose of putting the client at ease ...Often, interviewers are focused on themselves or make the assumption that nothing substantive is happening in this phase ... [T]he revelations most often were misheard (they often were sotto voce), or went unheard and unacknowledged ${ }^{35}$

The intervention training included helping students consider using probing questions which might uncover their client's emotional responses to their legal problem:

What are your greatest fears regarding the outcome in this matter?'

If this case turns out to your advantage, how will it affect your life?

If this case goes according to your worst case scenario, how will you be affected?

\section{Managing emotion}

Students watched videos of simulated legal interviews between clinical law students and actors in the role of clients. The videos were designed to activate the emotions of the students in a safe environment and to invite their thinking about how they might have conducted the interview in a real situation. ${ }^{36}$ One video involved a female student

\footnotetext{
${ }^{35}$ Gay Gellhorn 'Law and Language: An empirically-based model for the opening moments of client interview' (1998) 4 Clinical Law Review 321.

36 There were 4 videos which were developed specifically for the course. Each depicted a "typical client" scenario with a law student carrying out the interview. Actors were hired as clients and $5^{\text {th }}$ year law students performed the role of interviewer. A range of interview scenarios were devised which included one scenario played out 3 times with different questioning techniques designed to explore which techniques were the most effective in putting the client at ease and eliciting the most relevant information from the client.
} 
interviewing a male client who was angry about an offer of settlement from the opposing party. The video depicted the law student repeatedly advising the client that 'it's a good offer' and apparently ignoring the client's rising anger and disappointment. The interview was designed to help the students explore ways the interviewer could have tried different strategies to connect with the client and to calm him sufficiently to hear and accept the advice.

Class discussion included the interviewer's response to the client's anger. Some students identified strongly with the student interviewer and some admired her tenacity:

There were many aspects of the interviewer's performance in the clip that I liked. She remained calm and focused on the advice that needed to be heard by the client.

Asking students to consider whether the interviewer could have changed her approach produce a range of reflections:

I think she needs to actually acknowledge his concerns and then properly explain their position

It was suggested in class that the interviewer could have made more acknowledgement of the client's emotions. I think this was a really good suggestion ....

Students explored other techniques to reduce the impact of 'bad news' on the client or to deter or distract his rising anger in the first place, such as alternative ways of talking in order to prepare the client for disappointment. Overall the videos helped the students think about related content in the seminars and class discussions, which improved their awareness of their own emotional responses: 
I noticed from the video the client repeatedly slammed his hands against the lawyer's desk ... [he] repeatedly did this to express his emotions in the hopes of communicating his point clearly. As this occurred my emotions were outraged to a certain extent. I felt as though this client should be more grateful for the hard work being exercised by his legal representative free of charge. To this extent I had some initial feelings of anger.....

The seminars introduced the students not only to the advantages of emotional awareness in legal practice but also the problems emotions can cause if they are not well understood. We discussed the theory of 'amygdala flooding' and how intense emotions can prevent a client from being able to think clearly. ${ }^{37}$ Students were asked to imagine techniques they could use if the client was becoming too upset such as having a break to allow emotions to subside.

I think the message about 'pressing the pause button' would be extremely useful in diffusing the situation. Previously I would probably have been reluctant to do that as I would have worried that it would seem rude to the client. If done in a sympathetic manner, e.g. 'Would you like a glass of water' or .. 'let me get you a tissue', this could be really effective in calming down the situation.

In one exercise, ${ }^{38}$ we divided the class into two rooms, and showed each group the same projected visual image of an abstract painting while exposing them to different music, either dissonant and irregular sounds, or gentle and soothing music. Each group was then required to describe the picture. The group exposed to the soothing music used

\footnotetext{
${ }^{37}$ Alternatively 'amygdala hijacking' as used by Daniel Goleman in Emotional Intelligence: Why it can matter more than IQ (1996).

${ }^{38}$ This exercise was adapted from one presented by the Langley Group: Diploma of Positive Psychology and Wellbeing
} 
more positive and affirmative descriptions and generated more ideas about the painting than the other group. This led to discussion about how our workplace environment can impact clients' emotions including their ability to cope with 'bad news'.

We also discussed mindfulness as a strategy to help students manage their own emotions. Careful to distinguish it from any religious associations, mindfulness was presented as a practice to develop self-awareness, reduce anxiety and improve cognitive performance. Several students acknowledged improved self-awareness as an important skill for legal practice, even if it meant accepting they were at an early stage of professional development:

(Before the intervention...) the only way I could cope was to stop caring, emotionally I had to switch off. Even though I could recognise this, I was powerless to change it as I didn't know any other way to reconcile my emotions ...

Class discussion included the implications for the client of the interviewer 'switching off' when things got bad and what impact that could have on the professional relationship. ${ }^{39}$ Further discussion involved alternative strategies for managing stressful emotions during the interview, including acknowledging the feelings with the client, taking a break, getting support from a supervisor, and writing a reflection on the situation later. Some students were aware of the psychological value of written reflections through journal keeping:

\footnotetext{
${ }^{39}$ Rudolph J. Gerber, Lawyers Courts and Professionalism (Greenwood, 1989). Paula J. Manning, 'Understanding the Impact of Inadequate Feedback: A Means to Reduce Law Student Psychological Distress, Increase Motivation, and Improve Learning Outcomes' (2013) 43(2) Cumberland Law Review 225
} 
To deal with the emotional stress of dealing with unhappy clients and their problems, writing about how I feel would definitely help, as I already keep a diary daily, and have since $2004 \ldots$

Near the end of the training, several students acknowledged how the discussions and reflections helped them understand they were not alone, and that as a lawyer it is acceptable to seek help if necessary to manage emotionally stressful situations:

If as a lawyer you were coming into contact with situations of high emotion on a regular basis, it may be necessary to reach out to friends or qualified support people....it may be necessary to talk about your feelings especially if you begin to find them exhausting or particularly draining.

\section{THE RESEARCH RESULTS}

\section{Responses from clients}

The control group in 2013 involved 116 returned client interview questionnaires, of which 15 were discounted ${ }^{40}$, leaving 101 questionnaires for analysis. In the intervention group in 2014 there were 113 returned questionnaires of which 6 were discounted leaving 107 to be analysed.

\section{Qualitative analysis}

The qualitative analysis drew from the comments of the participating clients and students in order to identify themes, patterns and significant experiences and insights that might

\footnotetext{
${ }^{40}$ Questionnaires were discounted where the respondent had circled all the same numbers (when question 3 was reverse orientated) or had failed to complete the questionnaire at all.
} 
improve the clinical teaching, professional supervision and organisation of the clinical legal practice. Not every client took the opportunity to answer the qualitative responses in the questionnaire (the 'improvement question' and the 'explanation question'). Clients in both years referred to similar interviewing skills or qualities in their interviewing students, which they appreciated. They referred to the importance of the interviewer 'listening' to them (this was mentioned many times), showing 'empathy' towards them and demonstrating 'professionalism' (although this was not defined by the clients). Many also commented upon the 'appearance' of the interviewer.

Some clients particularly noticed whether or not the student smiled suggesting at least some clients appreciated a degree of friendliness or positive affect by the interviewer. For example:

perhaps a bit of a smile and friendly engagement in between serious attentiveness and concentration - not a biggy

Good eye contact, and listening skills but detached slightly not friendly but was unjudgmental may be smiling would help? Deadpan face

More smiles! Very efficient

They should practice more in getting the interview into an easier situation by a bit of a smile or show some enthusiasm on what the topic and problem is about...

Several clients referred to the 'complexity' of their problem, suggesting their difficulty in explaining it to a student and their need to be seen as unique or special.

They were attentive and showed understanding and seemed to have a reasonable grasp of a complicated and uncommon situation 
Reviewed Article: Teaching and Learning in Clinic

...this is a very lengthy case and very very complicated situation that the students came into contact with

Honestly my matter is quite complex. It need to be broken down and I don't know how to do it

I had many issues, too big for one session

....complicated matter and the student did a good job of giving understanding to solicitor, it was clear that meet with solicitor too complex

Part of our analysis involved categorising clients' responses to each question as 'positive', 'negative' 'mixed' or 'neutral'. For example, a suggestion that the student could improve as an interviewer was coded as a negative response whilst a suggestion that the students had no need to improve was coded as positive. Examples of positive responses included: I thought the student reasoned well and has a good manner. They were attentive and showed understanding and seemed to have a reasonable grasp of a complicated and uncommon situation;

I thought the students interviewing strategies were well developed and no need for improving at this time

Examples of 'negative' responses were:

Not sure of relevance with case but didn't ask too much about my life in general which may have some underlying influence/support to defend my case;

When relaying summarising needs to ensure that it is correctly relayed or it can come across as being vague/disinterested

Client responses suggesting students were good but improvement was still needed were assessed as mixed responses, such as: 
(the student) showed a great listening skill and communication but probably forgot to summarise what we discussed other than that seemed genuine

Some answers were categorised as "neutral" such as: "satisfied in general but student did not have time to explain to solicitor as they just came in"

The 'improvement question' (suggestions from the client on how the student could improve) is shown in Figure 2 with percentages for the five categories.

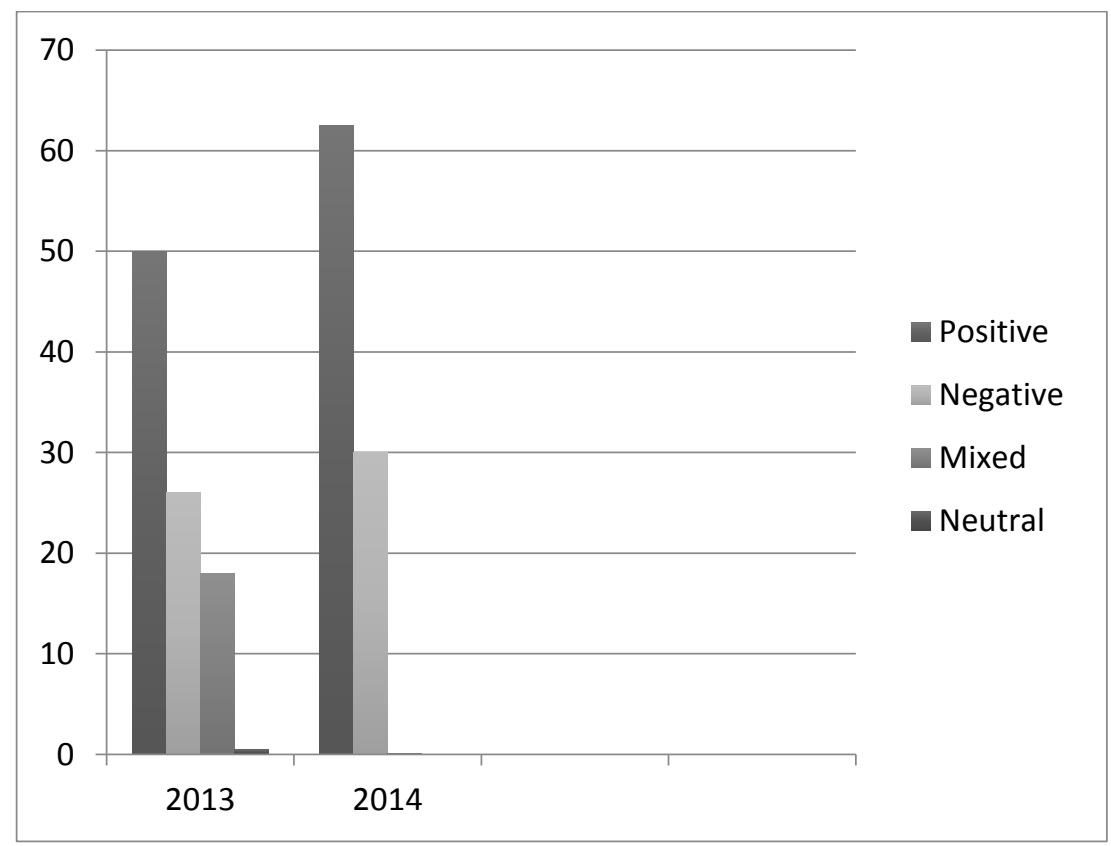

Figure 2. Numbers of clients who provided positive, negative, mixed or neutral responses to the 'improvement question'.

The 'explanation question' (where the clients gave an explanation for some of their answers in the questionnaire) were similarly coded and the percentage results are shown in Figure 3. 


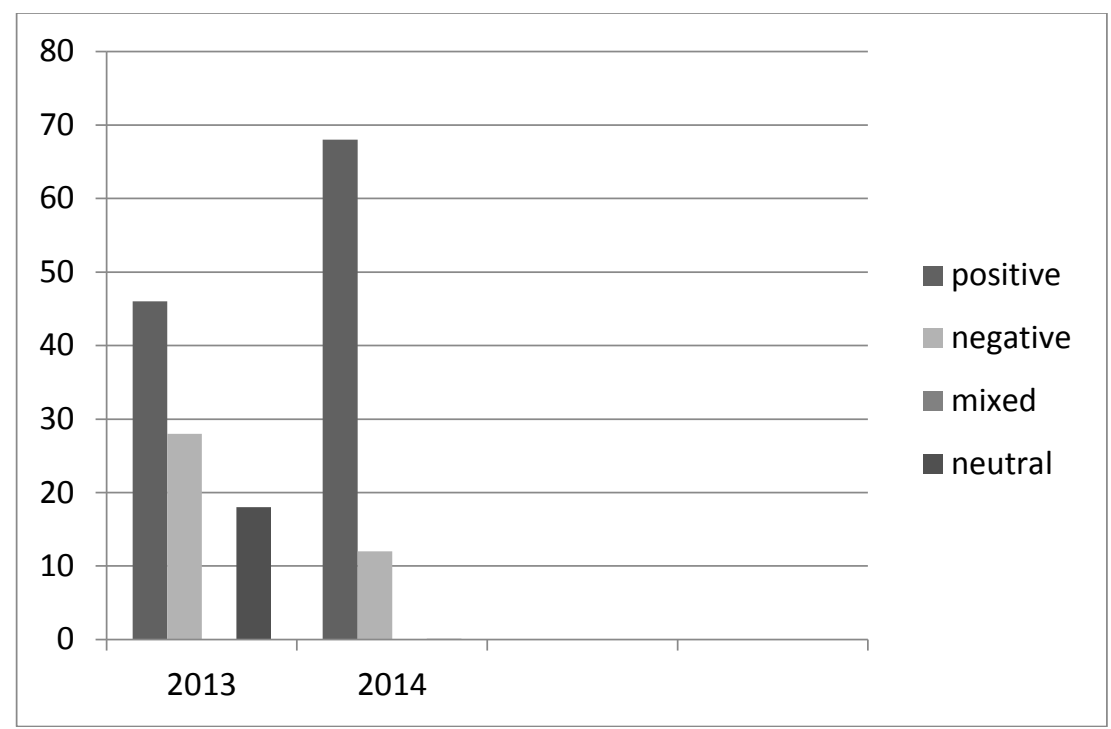

Figure 3. Numbers of clients who provided positive, negative, mixed or neutral responses to the ‘explanation question'.

The participant numbers are not large enough for statistical significance however the indicating trends suggested the intervention group (2014) conducted interviews that produced more positive responses from clients than did the control group (2013).

\section{Qualitative responses from supervisors and students}

The questionnaires for students and for supervisors also invited qualitative responses. However only a few supervisors and students took the time to complete this section, and few answers adequately addressed the issues to assist the research aims. The central focus of the students and supervisors was understandably on assisting the clients with their real, and sometimes urgent, legal problems.

\section{The quantitative Responses - results}

The quantitative responses from the clients' questionnaires over both years were entered into an excel database and forwarded to a consultant who performed a statistical analysis 
looking for relationships between the control and intervention groups to evidence significant differences that could have resulted from the intervention. While there were some particular questions which trended towards significance, overall, despite using different tests, there was insufficient statistical evidence to support the hypothesis. ${ }^{41}$

\section{Results of the STEU test}

As mentioned above, the STEU test is designed to measure one aspect of EI, the ability to understand emotion. We asked every student in the control group and the intervention group to take the STEU test before the research began and after the research ended. There was no significant difference in the students before and after the research in either the control group or the intervention group. In addition, the difference between the control and intervention group at both times was not statistically significant.

There are several reasons for a null result in the STEU test. First, the STEU test is relatively simple compared with the MSCEIT which is more extensive and therefore likely to be more sensitive to changes in a cohort. Second, the intervention might have not elicited changes in emotional capacity of the students in the intervention group that could be detected by the STEU test, although there were significant beneficial changes in those students identified in the qualitative assessment described below. Thirdly, as discussed in the limitations, the numbers used in both groups were very small compared with numbers often used for quantitative research comparing before and after results.

41 The consultant's analysis is available for inspection on request. 


\section{Discussion: Student reflections on their learning}

Despite the lack of statistical significance, the qualitative findings from the student reflections suggest the intervention group gained significant benefits in their training in terms of increasing their EI awareness and abilities. For many students this involved a difficult transition where they were confronted with the need to reconsider their presumptions, for example that a client's narratives will always be consistent:

.. when, I found out that this other information that did not fit into her story, I actually felt a little betrayed. This weird sense of betrayal brought on a reluctance to work on her case

This type of confrontation helped some students to grapple with their own self-concept, being able to adjust and be more flexible in how they presumed clients would see them:

This encounter also encouraged me to really 'get over myself' and realise that as an interviewing lawyer sometimes you are going to have to accept that clients may be unable to communicate completely respectfully. In such a circumstance, I now feel that it is more important to engage with the client and not expect endless amounts of respect.

Several students were able to articulate their experience of change and development as a result of events during an interview.

At this point in the interview I noticed myself becoming acutely aware of my feelings and my body language. I extended my lean forward towards the client in an effort build rapport and provide some comfort. However, reflecting on the lecture ....it was an effort to conceal my own insecurity and estrangement from the situation. .... felt helpless ...

Others reflected on their acquired belief in the importance of emotional regulation and how to appear when conducting a client interview: 
Reviewed Article: Teaching and Learning in Clinic

I recognised that it was in the best interests of the [client] that I look engaged and that it was my duty to be composed. Along with the change in my physical body language I adopted a softer voice in my questioning and became increasingly conscious of the timing of any sensitive questions...

Many students described how they were able to determine the emotional states of their clients at different stages of the interview, and reflect on what that might mean for their developing practice as a lawyer:

You could actually see the comprehension on the client's face, and though she was not overly happy with some of the things she was told, her relief was apparent...

The client came in visibly anxious with an edge of anger or possibly frustration. ... the client's speech .. was rushed and pointed... sat hunched with their arms crossed and spoke quickly in a loud and impatient manner, ending most sentences with a rhetorical question....

This led to a change in the emotions of the client from anger to sadness and resignation as the speech slowed down and grew softer whilst the body language was more slouched and defeated.

In terms of dealing with or responding to emotions, some students showed they had understood the theories of emotions we had discussed in the seminars and were motivated to practice strategies likely to develop their emotional competencies.

I was very conscious of my body language making sure I was leaning forward, giving eye contact and trying to be as sincere as I could at particular times (I found this difficult as my clients emotions spiked quite radically so I was never certain of exactly how to respond to things she said) portraying active listening at all times.... 
Several students distinguished their genuine feelings from the feelings they wanted to project to the client, noticing the differences were not always significant or relevant and they could often be emotionally sincere and professionally responsible:

I wanted to make sure that I portrayed to her that I understood how tough it must have been. Although I did feel genuine empathy for her as her situation was really unfair. I wanted to make sure that she knew that I understood her. I thought back to some of the skills that we had been taught over the last two weeks.

Some students focused on technique, and detailed how their interview methods seemed to affect the client and the communication flow:

I let her talk until it seemed like she had got everything out before I started asking questions. I kept eye contact and leant forward...I found that in taking the time to show respect for the client's emotions helped us to communicate better ....

Other students had more challenging interviews where the client was particularly emotional. Often in these cases, the student used the reflection process to augment their development with ideas on alternative strategies that might result in better interviews in similar cases in future:

Her tone was also dismissive, and every time I or someone else at the table tried to steer the conversation back towards the actual legal issue, (she) kept trying to cuss out and be negative about $Y$ 's conduct as if she was trying to get to us to agree that $Y$ was a bad person. I feel that I probably could have used a different way of questioning or talking to her in a way that both allowed her to get it off her chest but also moved our time on productively. 
Overall, the opportunity for the students to develop through their reflections on their live-client interviews in the context of the incremental training on emotional competencies through the seminars was the most valuable part of the intervention. The supervisors responded personally to each reflection to help ensure students felt encouraged, and more informed about the importance of emotions in legal practice broadly, not only in client interviews.

\section{Conclusion}

This project sought to develop and apply a method of enhancing students' emotional competency and to test whether teaching EI competencies to law students in a clinical legal setting would measurably enhance the clients' experiences of their first interview. Whilst our quantitative data was inconclusive, the qualitative findings were sound and provided insights into the value of EI competency training for law students. These results can be used to enhance professional development training in clinical programs and form a basis for future research. The reflection journals evidenced that many students improved their understanding and developed abilities during the intervention training, including their abilities to notice and reflect on their clients' emotional responses as well as their own. The project supports the embedding of EI competency training into clinical legal education or professional legal training programs in a more sustained manner to improve students' professional development and abilities to work with clients effectively and empathetically. 


\section{E LIMITATIONS}

The research was conducted during a busy legal clinic, which was not suited for a research project. Of necessity, the research had to be conducted over two years using different cohorts of students and clients, the 2013 student cohort as the "control" group and the 2014 student cohort as the intervention group. While both student groups had similar characteristics in terms of gender break-up, age and education level, we could not control for personality differences (likely to have significant effects in small cohorts) or law school programing and interview scheduling differences. Similarly, uncontrollable differences in personality of client and types of case in each year meant that small differences might have significant effects when using low numbers.

A significant structural limitation here was that in 2013 more than one student interviewed the client, in fact up to three students were in the interview room with the client, whilst in 2014 only one student interviewed the client in most cases. This was an unavoidable product of University scheduling. Any difference in the 2014 group as a result of the intervention training was, according to the statistical consultant, 'masked' by the effects of those students conducting interviews alone, compared with the teambased interviews in 2013.

Further, the overall sample sizes were small using data from just over 100 interviews in each year, which made it difficult to reach significant results. For statistical difference, future research needs to consider a design that collects from more interviews, with more 
students in a single clinical program, ideally over the same period. The control group could be offered the intervention training after the research period.

Finally, we could not control for the participant bias from the clients' apparent willingness to please, indicated by some giving positive answers to all questions. It is possible that clients attending a free clinic with young nervous students were not inclined to criticise the students' performance, despite being informed of the confidentiality of their responses and the value of the research to the students' professional training. It is also possible some clients were getting legal advice for the first time in their life and could not compare the experience of the interview with anything in order to assess the student's performance. Some clients, for example, used the questionnaire to praise their student rather than provide useful information:

A wonderful service, I felt my situation was validated and handled in a professional matter. Thank you.

I feel that the whole experience was of a great assistance to me it helped me to feel more at tease with the situation many thanks to the students who participated in the interview. just keep it up

\section{Future Research}

This project has several implications for future research that seeks to measure the effects of interventions designed to improve the emotional capacity of legal clinic students. If future research adopts a comparative analysis using a control groups as undertaken here, 
care should be taken to ensure the nature of the clinic situation under focus - here the client interviews - are comparable in structure. As stated above this problem was outside the control of the researchers in this study and produced a limitation to the results.

The researchers believe that clients' experiences are important and should be included in future studies, however researchers should identify methods that minimise the effects of participant bias. Specifically, we would urge caution about using surveys as part of the methodology. The conflicting factors of the clients' emotions, especially their anger, sadness, fear and confusion surrounding their legal case, and their gratitude and willingness to help the clinic students are likely to interfere with the accuracy of their surveys. A viable alternative might be inviting clients to be interviewed by researchers after being interviewed by the student, even though that would raise the problem of participant bias - upset or highly emotional clients would probably not agree to participate, and others might agree for fear of not seeming appreciative of the free legal help.

Capturing a richer, more nuanced and more accurate picture of the clients' experience of the student interview is a challenge particularly when the chief concern of a working clinic is to provide a legal service, modelling best practice including client care and confidentiality. The authors suggest that inviting clients to attend a focus group meeting in a relaxed setting, where the research questions could be explored more thoroughly, is worth considering if the participant bias can be adequately addressed. 